\title{
Egg-dumping by the Moorhen, Gallinula chloropus, in Japan
}

\author{
Keisuke UEdA ${ }^{1}$, Hiroshi Uchida ${ }^{2}$ and Takashi Matsuda ${ }^{3}$ \\ ${ }^{1}$ Laboratory of Biology, Rikkyo University, Nishi-ikebukuro 3, Tokyo 171 \\ ${ }^{2}$ Matsubacho 4-2-14, Higashi-Matsuyama, Saitama 355 \\ ${ }^{3}$ Omiya Chuo High School, Saitama 331
}

\begin{abstract}
The Moorhen Gallinula chloropus is a well known intraspecific brood parasite. However, there has been no reports on brood parasitism of the Moorhen in Japan. During a 8-yr field study of marsh nesting birds in Akigase marsh, central Japan, we found some Moorhen nests which contained abnormally large number of eggs (super-normal clutch) and we obtained evidence of intraspecific brood parasitism and/or cooperative nesting. Moorhens were unable to distinguish between foreign (Japanese Quail and conspecific) and their own eggs. A proximate cause of frequent egg dumping may due to the high breeding density in the habitat. This is the first report on the egg-dumping in a Japanese population of the Moorhen.
\end{abstract}

Key words: Brood parasitism, cooperative nesting \& super-normal clutch.

In a number of bird species, some females take a reproductive short-cut by laying eggs in the nest of conspecifics (Yom-tov 1980, Andersson 1984). The Moorhen Gallinula chloropus is well known as an intraspecific brood parasite in England (Gibbons 1986, Petrie 1983, 1984, 1986). However, there has been no reports on brood parasitism of the Moorhen outside England. Harato (1989) conducted a detailed study of the breeding biology and social structure of the Moorhen on Okinawa Island, but did not find egg dumping. During a 8-yr field study of marsh nesting birds, we found some Moorhen nests which contained abnormally large number of eggs and we obtained evidence of intraspecific brood parasitism and/or cooperative nesting. We report here the first cases of egg-dumping in a Japanese population of the Moorhen.

\section{STUDY AREA AND METHODS}

Field work was conducted over eight breeding seasons (May to August), 19861993. The study area was the Akigase paddy field in Saitama prefecture, $30 \mathrm{~km}$ north of Tokyo $\left(35^{\circ} 50^{\prime} \mathrm{N}, 139^{\circ} 37^{\prime} \mathrm{E}\right)$. This 47.2 ha paddy field is made up of grasslands, cattail Typha angustata marshes, small swamps and reed Pharagmites communis beds. Many marsh nesting bird species, including the Moorhen, nest in this area (e.g. the Yellow Bittern Ixobrychus sinensis, the Great Reed Warbler Acrocephalus arundinaceus, and the Schrenck's Reed Warbler A. bisrigiceps). In the course of nest searching in the area from 1989 to 1990 , we found 16 nests of the Moorhen. In three seasons between 1991 and 1993 we intensively searched for Moorhen nests in a small cattail marsh $\left(\right.$ c. $\left.920 \mathrm{~m}^{2}\right)$ in the area.

Once a Moorhen nest had been located we checked its contents daily or every two days to determine the number and the sequence of eggs laid. To the extent possible an attempt was made to mark each egg on the day it was laid. We recorded any 
evidence that more than one female had laid in a nest, such as (1) an extraordinarily large clutch (super normal clutch $=\mathrm{SNC}$ ), (2) eggs laid after the host female had completed her own clutch, or (3) two or more eggs laid in one day, as females usually laid an egg daily in the afternoon or in the evening during the egg laying period. We regarded the clutch has been completed when egg laying was interrupted in two or more days.

The normal clutch size (no. of eggs laid in a nest by a single female) was 5.3 (range $=2-8$ ) in Okinawa (Harato 1989) and 6.8 (range=4-10) in England (GibBons 1986 ) on the average. Clutch size of many bird species tends to increase with latitude (e.g. LACK 1954, KLOMP 1970). We regarded any clutch of more than nine eggs as a SNC in this area, since this study area $\left(42^{\circ} \mathrm{N}\right)$ is located between Okinawa $\left(26^{\circ} \mathrm{N}\right)$ and England $\left(52^{\circ} \mathrm{N}\right)$ in latitude.

We performed experiments for examining the response of nest owners to foreign eggs in 1991 and 1993. First, we set eggs of the Japanese Quail Coturnix coturnix in brood nests (beds for chicks which are made in the territory: see HaRATo 1989) of the Moorhen. In the second experiment we added two conspecific eggs to the active nests in incubating stage.

\section{RESULTS}

Sixteen nests of the Moorhen were found in study area between 1986 and 1990. Of these nests, 11 were active nests (i.e. had at least one egg). Of these active nests, 10 subsequently had complete clutches (Table 1). The clutch sizes of seven nests were fell within the range of normal clutch size, five to eight $(6.57 \pm 0.98(\overline{\mathrm{x}} \pm \mathrm{SD}, n=6))$. However, three nests had extraordinary large clutches (SNC) of 10,11, and 15 eggs, respectively.

We intensively searched for nests from 1991 to 1993 and found 16,15 , \& 18 nests in the three years, respectively. Of those nests, 15 (93.8\%) in 1991, $12(80.0 \%)$ in 1992 $\& 10(55.5 \%)$ in 1993 were found in the cattail marsh. A total of 16 nests were filled by complete clutches. The average clutch size of these normal nests was $7.40 \pm 1.07$ $(n=10)$. Six SNC nests and one possibly parasitised nest were found. Of the SNC nests, three found in 1991 had 10,12 and 15 eggs, one in 1992 had 20 eggs, and two in 1993 had 23 and 15 eggs, respectively (Fig. 1).

A nest with six eggs being incubated was found on 1 July 1991. One egg was added on 3 July. It is not likely that the egg was the 7 th egg of the nest owner, because the three chicks hatched successively on the 6 th, 7 th and 11 th July, respectively. The remaining four eggs were deserted and one was destroyed 17 th July. The added egg was regarded as a parasite egg.

Table 1. Number of eggs laid in the Moorhen nests with complete clutches

\begin{tabular}{|c|c|c|c|c|c|c|c|c|c|c|c|c|}
\hline & \multicolumn{12}{|c|}{ No. of eggs laid } \\
\hline & 5 & 6 & 7 & 8 & 9 & 10 & 11 & 13 & 15 & 20 & 23 & Total \\
\hline $1986-1990$ & 1 & 2 & 3 & 1 & & 1 & 1 & & 1 & & & 10 \\
\hline 1991 & & & 1 & 1 & & 1 & & 1 & 1 & & & 5 \\
\hline 1992 & & 1 & 2 & & 1 & & & & & 1 & & 5 \\
\hline 1993 & & 1 & 1 & 1 & 1 & & & & 1 & & 1 & 6 \\
\hline Total & 1 & 4 & 7 & 3 & 2 & 2 & 1 & 1 & 3 & 1 & 1 & 26 \\
\hline
\end{tabular}




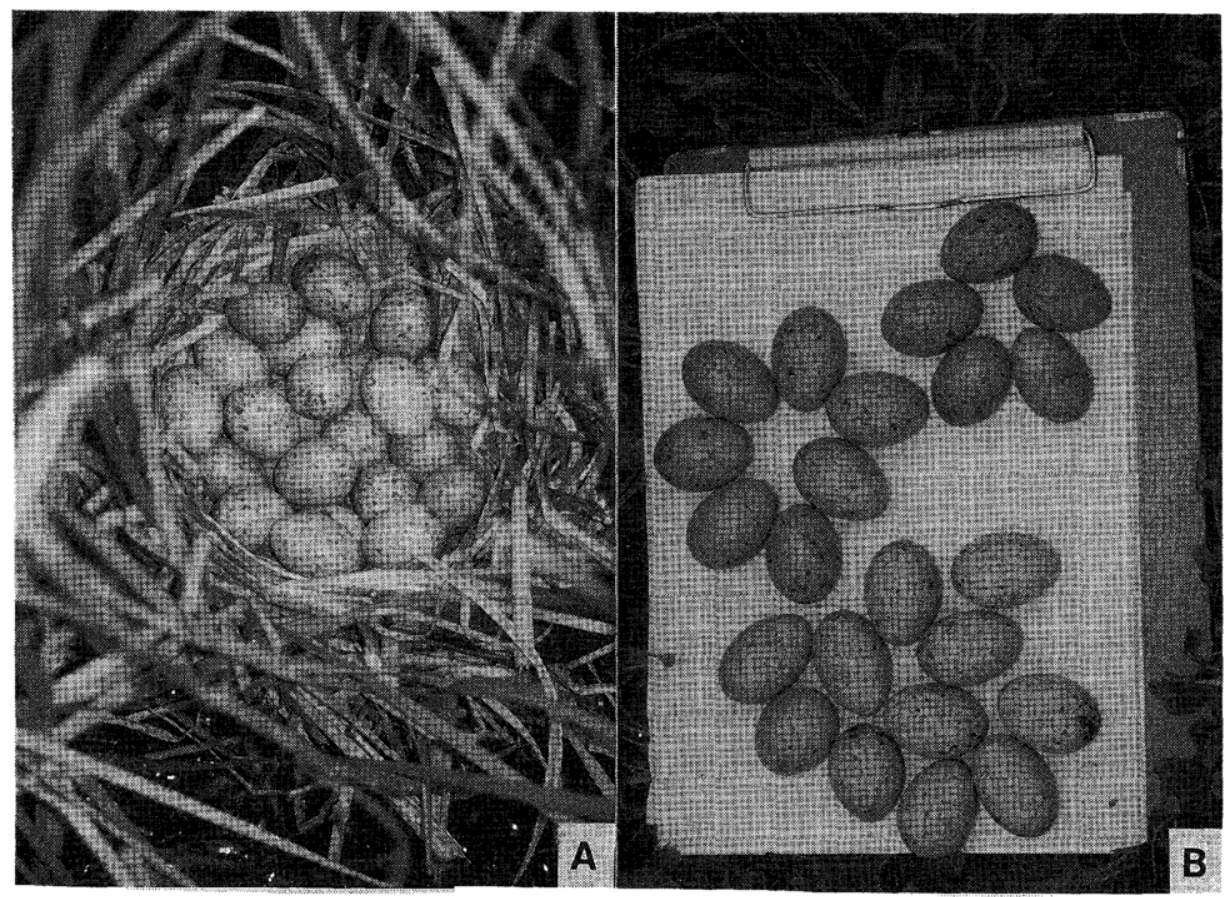

Fig. 1 A) Dumped nest containing 23 eggs found in 1993. B) Three types of eggs with diffrent colour, size, and shape variation in a single clutch of the 23-egg nest.

Eggs in SNC nests differed in size (volume and weight), shape and colour. In one SNC nest found in 1991, the last two (9th \& 10th) eggs were different in shape and colour from the rest of the clutch. We were able to divide the 20 and 23 eggs found in SNC nests in 1992 and in 1993 into three groups of eggs of different size and colour, respectively (Fig. 1B), suggesting that these two clutches may have been laid by more than two female. However, even in some nests containing a normal-sized clutch, we found considerable variation in the shape and colour of eggs. Although these eggs were laid in nests showing a normal laying sequence, this could be due to egg removal and addition by parasitic females before laying their egg. Hence brood parasitism may occur even in a nest with a normal clutch.

We tested the response to foreign eggs added to brood nests on 18 June, 1991. Three and four Japanese Quail eggs were added to two brood nests, respectively. By the next day, all three eggs were destroyed and the contents eaten in one nest, and all four eggs disappeared from the other. This suggests that egg removal and/or egg eating by nest owner occurs in the brood nests.

In 1993 we added two Japanese Quail eggs to three active nests with normal clutch, respectively. However, these foreign eggs were left untouched two days after the experiment in these active nests. We also added two conspecific eggs to two active nests with normal clutch, respectively. Again in these cases, added eggs were not removed, suggesting that nest owners were never discriminate between foreign and own eggs. 


\section{DISCUSSION}

Five of six SNC nests were found in a small cattail marsh. Egg dumping and/or brood parasitism were rare in nests built outside the marsh. At least three pairs and/or groups were breeding in ca. $920 \mathrm{~m}^{2}$ swamp. HaRATo (1989) reported that a home range of a pair was $2600 \mathrm{~m}^{2}$, on average. Moorhens inhabiting in the cattail marsh went outside the marsh for foraging. However, nest site was restricted to the marsh. A proximate cause of frequent egg dumping in this population of the Moorhen may have been the high breeding density.

The social causes of egg-dumping in the moorhen could be ascribed to two features of their breeding biology: (1) polygynous nesting with two or more females paired to the same male, and (2) intraspecific brood parasitism with some females (parasites or dumpers) laying a small number of eggs at random in neighbouring nests (GiBBons 1986). In the study made in England, the number of eggs in dumping nests varied from 7 to 21 and in parasitised nests from 6 to 16 .

GibBons (1986) proposed that brood parasitism could be detected by comparing the colour and shape of eggs laid in the nest, because the appearences of eggs are different among females. This method was not applicable to our study, because we sometimes found egg of different colour and shape in nest with normal clutch sizes. When checked and marked daily in some nests, these eggs seemed to belong to a single female based on the laying pattern determined by checking the nest contents and marking eggs. Though there is a possibility that the eggs were predated, a parasitic female may remove or eat one or more of the host's eggs before she lays, as found in parasitic cuckoos. Plater (1969) and Harato (1989) observed Moorhens fed own eggs to chicks. Our experiment on brood nests suggest that the cause of the disappearence and destruction of foreign eggs in the brood nests may be ejection by nest owners or parent feeding for chicks. However, in two egg-adding experiments, 'hosts' were torelant to the 'parasite eggs'. More detailed observations on the breeding behaviour of the Moorhen are needed to determine which females in the population lay the parasitic eggs.

We thank Leah N. deForest and Carola A. HAAs for improvement of English in earlier manuscript and for their helpful comments and discussions. Tetsujiro Harato kindly sent us his MS Thesis on the Moorhen.

\section{LITERATURE CITED}

Anderson, A., 1984. Brood parasitism within species. In Barnard C. J. (ed) Producers and scroungers; strategies of exploitation and parasitism. pp. 195-228. Croom Helm, London \& Sydney.

GibBons, D. W., 1986. Brood parasitism and cooperative nesting in the moorhen, Gallinula chloropus. Behav. Ecol. Sociobiol. 19: 221-232.

Harato, T., 1989. Breeding biology and social structure of the Moorhen, Gallinula chloropus indica, in Okinawa-jima Island, Japan. MS Thesis of Ryukyu University. (In Japanese with English summary).

Klomp, H., 1970. The determination of clutch-size in birds. Ardea 58: 1-124.

LACK, D., 1954. Natural regulation of animal numbers. p. 343. London, Oxford Univ. Press.

Petrie, M., 1983. Female moorhens compete for small fat males. Science 220: 413-415.

Petrie, M., 1984. Territory size in the moorhen (Gallinula chloropus): an outcome of RHP 
asymmetry between neighbours. Anim. Behav. 32: 861-870.

Petrie, M., 1986. Reproductive strategies of male and female moorhen (Gallinula chloropus). In Rubenstein, D. I., \& Wrangham, R. W., (eds) Ecological Aspects of Social Evolution: Birds \& Mammals. pp. 43-63. Princeton Univ. Press.

Plater, L., 1969. Moorhen feeding own eggs to chicks. Brit. Birds 62: 116.

Yom-Tov, Y., 1980. Intraspecific nest parasitism in birds. Biol. Rev. 55: 93-108.

(Accepted 25 August 1993) 